\title{
Endoscopic ultrasound-guided gallbladder drainage to facilitate biliary rendezvous for the management of cholangitis due to choledocholithiasis
}

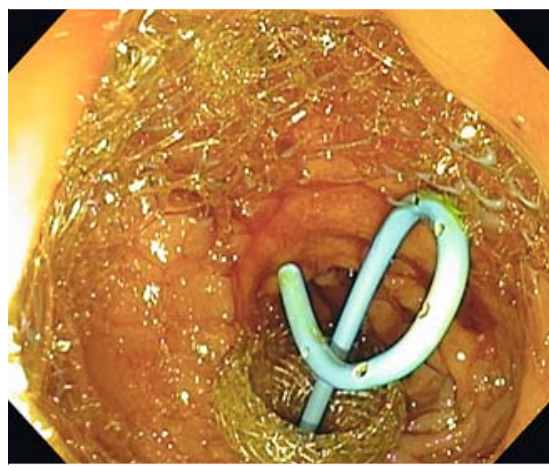

- Fig. 1 Endoscopic view of the cholecystoduodenostomy to facilitate relief of biliary obstruction during the index procedure.

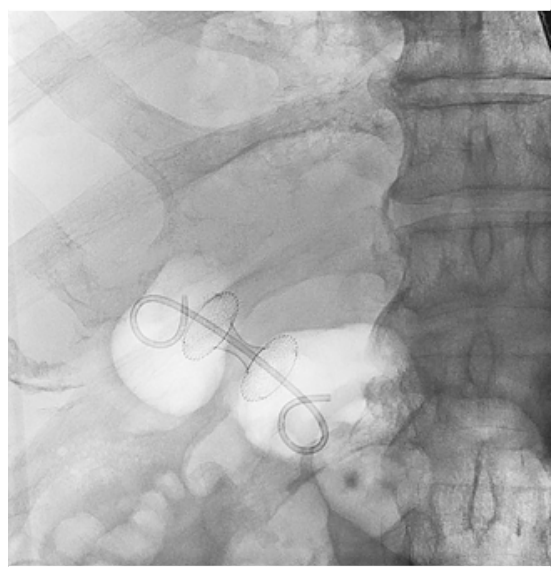

- Fig. 2 Fluoroscopic view of the cholecystoduodenostomy using a lumen-apposing metal stent with double-pigtail plastic stent within.

An 81-year-old man presented with upper abdominal pain, nausea, and vomiting, with elevated liver test results. Abdominal computed tomography demonstrated mild intra- and extrahepatic biliary ductal dilation (common bile duct $11 \mathrm{~mm}$ ), with choledocholithiasis, layering gallstones, and enhancement and thickening of the gallbladder wall. Endoscopic retrograde cholangiopancreatography (ERCP) was attempted, but biliary cannulation of an intradiverticular papil-

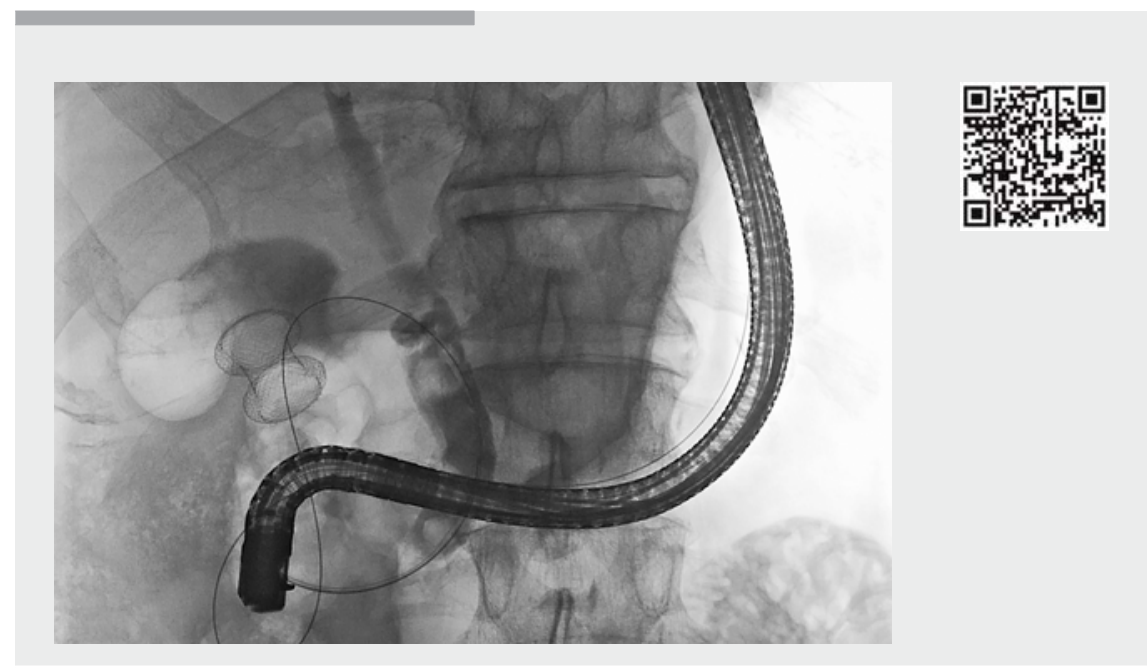

Video 1 Endoscopic ultrasound-guided gallbladder drainage to facilitate biliary rendezvous for the management of cholangitis due to choledocholithiasis.

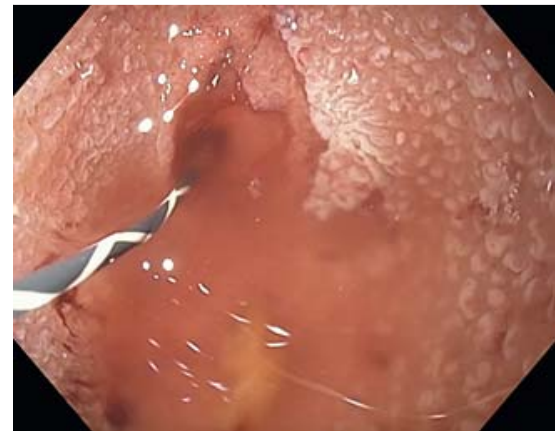

- Fig. 3 Endoscopic visualization of the gallbladder neck during guidewire passage.

la failed, despite precut sphincterotomy. Endoscopic ultrasonography (EUS)-guided gallbladder drainage provided initial biliary decompression. Subsequently, biliary rendezvous via the gallbladder conduit facilitated conventional ERCP with sphincterotomy and stone extraction, as described below ( $\vee$ Video 1 ).

After failed ERCP and during the same endoscopic session, an oblique-viewing, linear-array echoendoscope (Olympus, Tokyo, Japan) was passed in anticipation of biliary rendezvous. A decision was

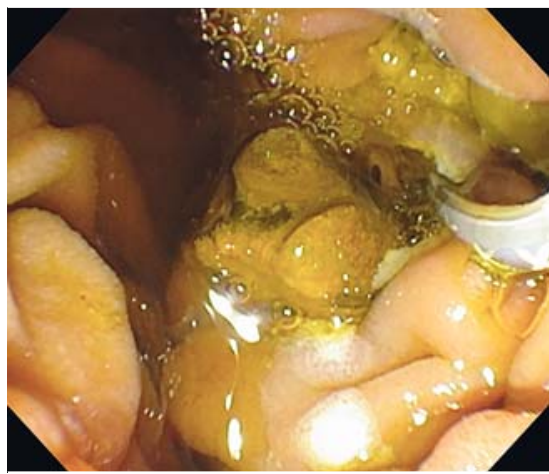

- Fig. 4 Removal of stones from the common bile duct following successful biliary rendezvous procedure via the cholecystoduodenostomy.

made to perform biliary decompression via the distended gallbladder, to address underlying cholecystitis in this poor operative candidate. Cholecystoduodenostomy ( $\triangleright$ Fig. 1) was performed using a 19 G needle (Expect; Boston Scientific, Marlborough, Massachusetts, USA) for access, aspiration, and contrast injection. A 0.025 inch guidewire, $450 \mathrm{~cm}$ in length (VisiGlide; Olympus America, Center Valley, Pennsylvania, USA) was coiled 
into the gallbladder. Over the wire, a cautery-enhanced, $10 \mathrm{~mm} \times 10 \mathrm{~mm}$, lumenapposing metal stent (LAMS; Axios; Boston Scientific) was deployed, and a $7 \mathrm{Fr} \times$ $4 \mathrm{~cm}$ double-pigtail plastic stent was placed within the LAMS ( Fig. 2).

The double-pigtail stent was removed 7 weeks later, and a standard gastroscope was advanced through the cholecystoduodenostomy into the gallbladder neck ( $\triangleright$ Fig.3). A stone retrieval balloon catheter, preloaded with a 0.035 inch angled hydrophilic guidewire (Glidewire; Terumo, Somerset, New Jersey, USA), was passed antegrade through the cystic duct into the common bile duct, and into the duodenum. The wire was exchanged for a long wire. The gastroscope was exchanged for a duodenoscope, and rendezvous ERCP was successfully performed with biliary sphincterotomy and stone clearance (> Fig.4). Minimal gallstones remained. The LAMS was removed and replaced with two $7 \mathrm{Fr}$ double-pigtail stents for long-term gallbladder drainage.

\section{Endoscopy_UCTN_Code_TTT_1AS_2AD \\ Competing interests}

Dr. Baron is a consultant for W. L. Gore, Boston Scientific, Olympus, Cook Endoscopy.

The Authors

\section{Ryan Law ${ }^{1}$, Todd H. Baron ${ }^{2}$}

1 Division of Gastroenterology, University of Michigan, Ann Arbor, Michigan, United States

2 Division of Gastroenterology and Hepatology, University of North Carolina, Chapel Hill, North Carolina, United States

\section{Corresponding author}

\section{Todd H. Baron, MD}

130 Mason Farm Road, CB 7080, Chapel Hill, NC 27599-0001, United States

Fax: +1-994-974-0744

todd_baron@med.unc.edu

\section{Bibliography}

DOI https://doi.org/10.1055/s-0043-119351

Published online: 9.10.2017

Endoscopy 2017; 49: E309-E310

(c) Georg Thieme Verlag KG

Stuttgart · New York

ISSN 0013-726X

\section{ENDOSCOPY E-VIDEOS \\ https://eref.thieme.de/e-videos}

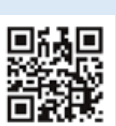

Endoscopy E-Videos is a free access online section, reporting on interesting cases and new

techniques in gastroenterological endoscopy. All papers include a high quality video and all contributions are freely accessible online.

This section has its own submission website at https://mc.manuscriptcentral.com/e-videos 